\title{
Disrupting the subscription journals' business model for the necessary large-scale transformation to open access
}

\author{
A Max Planck Digital Library Open Access Policy White Paper \\ Ralf Schimmer, Kai Karin Geschuhn*, and Andreas Vogler \\ Max Planck Digital Library, Amalienstraße, 33, 80799 München, Germany \\ *Corresponding author's e-mail address: geschuhn@mpdl.mpg.de
}

Published online: 10 June 2015 (version 1)

Cite as: Schimmer et al. ScienceOpen Research 2015 (DOI: 10.14293/S2199-1006.1.SOR-EDU.AJRG23.v1)

Reviewing status: Please note that this article is under continuous review. For the current reviewing status and the latest referee's comments please click here or scan the QR code at the end of this article.

Primary discipline Information \& Library science

Keywords Article-processing charges, Scholarly publishing, Journal subscriptions, Open access, Open access transition

\begin{abstract}
This paper makes the strong, fact-based case for a large-scale transformation of the current corpus of scientific subscription journals to an open access business model. The existing journals, with their well-tested functionalities, should be retained and developed to meet the demands of 21st-century research, while the underlying payment streams undergo a major restructuring. There is sufficient momentum for this decisive push toward open access publishing. The diverse existing initiatives must be coordinated so as to converge on this clear goal. The international nature of research implies that this transformation will be achieved on a truly global scale only through a consensus of the world's most eminent research organizations. All the indications are that the money already invested in the research publishing system is sufficient to enable a transformation that will be sustainable for the future. There needs to be a shared understanding that the money currently locked in the journal subscription system must be withdrawn and re-purposed for open access publishing services. The current library acquisition budgets are the ultimate reservoir for enabling the transformation without financial or other risks. The goal is to preserve the established service levels provided by publishers that are still requested by researchers, while redefining and reorganizing the necessary payment streams. By disrupting the underlying business model, the viability of journal publishing can be preserved and put on a solid footing for the scholarly developments of the future.
\end{abstract}

\section{INTRODUCTION}

The uptake of open access in recent years has been remarkable. Articles in open access are the most dynamic growth area in scientific publishing and have reached a market share of $13 \%$ (without even counting the hybrid component, which has also been growing rapidly as a result of British encouragement following the Finch report). In just a few short years PLoS One has become the largest journal in the world, both in the number of papers it publishes and in the citations it is attracting.

It is a truism among publishers that new journals nowadays can be brought to market only if they are open access; a new journal has no real future if it is placed on the subscription track. Though open access is taking its publication share away from the journals' subscription element, this tendency is not mirrored by a shift of costs from subscriptions to open access fees. At present, the costs for open access publishing services come as an add-on to a persisting subscription system that continues to extract annual price increases above inflation from the libraries of the world. It is not hard to predict that the acceleration of open access can be sustained only if the subscription budgets are opened up to be utilized for publication services as well. Furthermore, the final breakthrough to a comprehensive open access publishing system cannot be achieved unless library acquisition budgets are repurposed so as to consolidate the system's two current streams into a single undertaking: to provide the best possible publishing services for the patron researchers. This calls for the removal of the scarcities and restrictions that have been artificially imposed by the toll-access system. Therefore the next and perhaps final round in the evolution to a 21stcentury publication system must be the transformation of the existing subscription journals to a purely open access model. This will be achieved by converting the existing library acquisition funds into a budget for publication services, which can be expected to be eventually rather more stratified than article-processing charges (APCs) as we know them today.

The purpose of this paper is to assert the necessity of a largescale transformation of the current subscription journals to an open access business model and that this transformation can be achieved only by an equally large-scale transformation or liberation of the library acquisition budgets. We show that the money spent annually in the subscription system is already sufficient to accomplish this. The new fundamentals would 
enable the publishing regime to arrive in the digital era, and would also support both publishers and librarians to re-define their roles and to develop their professional scope. After years of widespread anxiety and stress, the framework for a modern, realistic, and sustainable system could finally be realized through a large-scale transition to a congruous business model.

\section{IMPORTANT BUT LIMITED INITIATIVES}

Since the start of the open access debate, various initiatives have brought changes to academic publishing, but they have all been limited in their scope and impact. Open access is making some progress, as seen in the uptake of the 'Gold' approach and the emergence of the particular example of Sponsoring Consortium of Open Access Publishing in Particle Physics (SCOAP3) as a model and inspiration. There is also increasing interest within the political sphere that reflects a push for better access to publicly funded research; and industry players have also been devising new approaches to open access. Nevertheless, the current subscription system still prevails and is even in good shape, which indicates the challenge of overcoming the inertia in an established system.

\section{Seeing the rise of open access}

In the past decade there has been significant increase in 'Gold' open access, the arrangement whereby researchers (or their institutions/funders) make advance payments of APCs to publish articles that are freely accessible in scholarly journals online. This increase is reflected in the output in pure open access journals, which has been growing steadily by $1 \%$ of total publications year on year. The current level is around $13 \%$ of total research papers, a surge that - interestingly continues regardless of the presence or absence of any policy and support structure at a given research institution.

The SCOAP3, hosted and organized by CERN, has blazed the open access trail by converting some of the most prestigious journals in its field of high-energy physics to open access. In modeling a switch of services and cash flows to open access mode, SCOAP3 has laid out an inspiring example to other research fields for the development of open access action plans of their own.

\section{Political momentum is increasing}

The open access approach is gaining increased political momentum. Various governments and national research councils, in the European context particularly, have recently defined their very ambitious goals of publishing between $50 \%$ and $80 \%$ - if not all - of their national research output as open access within the next 5-10 years. Policies, budget provisions, and administrative structures are being developed accordingly. And on the supranational level, bodies such as the Global Research Council or Science Europe are also pushing for more open access.

\section{The 'hybrid' approach is an evolutionary step}

Certain subscription journals have made an evolutionary step toward open access by offering some of their articles on an open access basis. While this approach is reassuring for publishers, since they also continue to receive subscription income, the article-processing costs tend to be high. ${ }^{1}$ Furthermore, there is concern about so-called double dipping, whereby an article is effectively paid for twice, through both subscription expenses and an APC, in a context in which publishers may not always be transparent about proposed reductions in subscription price. ${ }^{2}$ Many commentators have pointed out that a hybrid-supporting institution would - even with publishers' proposed reductions - get only very marginal monetary refunds for its investment.

\section{'Offsetting' models take hybridity into a creative new space}

In addition to an increasing uptake of the 'hybrid' model, which has added a substantial amount of individual free-toread articles in otherwise toll-access journals, we see the emergence of 'hybrid 2.0' in so-called offsetting models that redefine and extend the hybrid approach. As a result, perhaps, of the growing pressure from the influential European constituencies, several publishers have set up or are in negotiations to devise ways to re-frame the services for contemporary scholarly communication while also reorganizing the respective cash flows.

The rationale for offsetting models is that the defined open access services and their costs are (somewhat) set off against subscription spending. Given that this approach also requires the establishment of workflows for the handling of APCs, the offsetting models could pave the way in structural, financial, and organizational terms for further transitions. It could thus become a major catalyst for manifesting the modern, digital services that have been envisioned for today's scholarly communication, along with becoming a vehicle for re-organizing the respective cash flows, too.

The offsetting approach was pioneered in the 'Gold for Gold' program by the Royal Society of Chemistry and in an agreement between Austria and IOP Publishing in early 2014. Since then there has been a steady flow of similar announcements, with the biggest push coming currently from the UK and the Netherlands.

The model as such, of course, is in the early days of its evolution, and it has yet to be applied beyond the local or institutional level at an effective global scale. Nonetheless,

\footnotetext{
${ }^{1}$ Bo-Christer Björk, David Salomon (2014): "Developing an effective market for open access article processing charges". http://www.wellcome.ac.uk/About-us/Policy/Spotlight-issues/ Open-access/Guides/WTP054773.htm.

2 David Prosser (2015): "The costs of double-dipping". http:// www.rluk.ac.uk/about-us/blog/the-costs-of-double-dipping/.
} 
offsetting is a progressed version of the hybrid model, and promises for the first time to be a truly 'transitional' model. ${ }^{3}$ It therefore induces anxiety on the front line between advanced research libraries and conservative publishers because it has the potential to be a platform for the total overhaul of the financing of academic publishing.

\section{Pushing beyond the offsetting model}

Important though each of these developments may be, their overall impact has been inadequate. Offsetting can achieve only limited impact, and bold national initiatives such as those in the UK are insufficiently decisive to change the journals' underlying legal and financial structures. If we want to accelerate open access we need an ambitious transition plan, along with direction and concerted action that includes further cooperation among non-traditional allies.

On the occasion of the 10th anniversary conference of the Berlin Declaration, then President of the Max Planck Society, Peter Gruss, summarized the challenge by saying,

Instead of the black box of subscription price calculations, we need models based on actual publication costs and characterized by transparency and sustainability. The money from existing subscription budgets must be transferred to publication budgets from which the authors' publications can then be financed via open access. ${ }^{4}$

Innovation in the payment of publication costs cannot be fully expanded unless subscription costs are simultaneously eliminated or systematically transformed. The libraries' existing acquisition budgets must therefore be the crucial fiscal reservoir for such a transformation. All that remains for the implementation of this clear philosophy is to be assured that there is sufficient money in the system for such a switch to be feasible.

\section{Re-purposing the money currently invested}

Discussions about the transition from the current subscription-based model to an APC-based open access 'Gold' model have frequently raised anxieties about a presumed increase in costs. Libraries, in particular, very often fear that in the end they would need to pay more.

In most cases such perspectives arise from a lack of information about and analysis of the structure and distribution of scientific journal publishing. Monitoring publication data at either an institutional or a geographic level and looking for

\footnotetext{
${ }^{3}$ Stuart Shieber (2014): "A true transitional open-access business model". The Occasional Pamphlet on scholarly communication. https://blogs.law.harvard.edu/pamphlet/2014/03/28/ a-true-transitional-open-access-business-model/.

${ }^{4}$ Peter Gruss (2013): "The unstoppable rise of Open Access". Max Planck Research 4/2013, p. 7. http://www.mpg.de/ 7644861/S002_Spotlight_006-007.pdf.
}

insights is not yet a standard practice among libraries and other information service providers, since the necessary datahandling skills and statistical proficiencies are not readily available in these institutions. However, the expertise available at the Max Planck Digital Library enables us to bring some foundational evidence to the debate.

We firmly believe that a large-scale transformation of the underlying business model of scientific journals is possible at no financial risk. Our own data analysis shows that there is enough money already circulating in the global market money that is currently spent on scientific journals in the subscription system and that could be redirected and reinvested into open access business models to pay for APCs. This paper substantiates our assertion by presenting generic calculations we have made on the basis of available publication data and revenue values at global, national, and institutional levels.

\section{Global publishing and APC data}

As we know from various market reports by key analysts such as Simba and PNB Paribas, annual sales of academic journals throughout the world currently generate commercial revenues of approximately EUR 7.6 billion. This figure is at the lower end of what is being reported; a global annual spending level of US\$ 10 billion is also quite commonly referred to. In such commentaries, several major currencies are inevitably collapsed into one common denominator, causing a certain margin of error that may be exacerbated by the natural fluctuation of exchange rates. Having monitored the market for many years, we feel confident with the figure of EUR 7.6 billion (and we use EUR as reference currency in this document).

This level of spending corresponds to an annual research output of approximately 2 million journal articles, a frequently quoted figure that can be taken as a well-grounded assumption. ${ }^{5}$ Our own data analysis traced 1.45 million research articles in the Web of Science in 2013, roughly rounded up to 1.5 million research articles in 2014. Since the essence of the Web of Science is to index the world's most prestigious, largest, and most expensive journals, then all the many regional low-volume, low-profile, and low-cost journals that do not make it into the Web of Science can be considered as part of the long tail. The current annual output of 2 million research articles can therefore be viewed as roughly 1.5 million Web of Science recorded articles and 0.5 million additional articles.

If we were to consider the Web of Science's indexed research articles only, the amount spent per article in the current subscription system would be in the region of EUR 5,000. If all presumed articles were to be included, the allocation per

\footnotetext{
${ }^{5}$ Cf., for instance, STM Report 2014 (2015). http://www. markwareconsulting.com/the-stm-report/.
} 
article would be in the region of EUR 3,800. The reality will be somewhere in between. These calculations are shown in the following tables:

\section{(a) Web of Science annual articles calculation}

\begin{tabular}{ll}
\hline Global journal subscription spending & EUR 7.6 billion \\
Web of Science listed articles only & 1.5 million papers \\
Calculated expenses per article (rounded) & EUR 5,000 \\
\hline
\end{tabular}

(b) Total annual articles calculation

Global journal subscription spending

Total estimated articles output

Calculated expenses per article (rounded)

Insight 1

Under the current subscription system, a figure between EUR 3,800 and 5,000 is already being paid per research article through library subscription spending.

From what we know, it is safe to assume that in a predominantly open access publishing system the average article costs would not nearly be as high. Of course, it is conceivable that individual high-profile journals may have expensive production costs and would have to set their charges in such a range or perhaps even beyond, but - given the vast stratification of journals - such an 'elite' is a very small proportion of the total. In the emerging new realities we will see a widely distributed range of APCs, from the very low end to a very high end. Whether calculated as mean or median, however, the average APC index will never be dictated by the high-end values.

Research institutions and funders that have a support scheme for APCs in place are increasingly monitoring and reporting their spending data. For instance, we at the Max Planck Digital Library have begun to upload our APC data to a workspace on GitHub, provided by the OpenAPC initiative under the guidance of Bielefeld University. So far we have documented over 1,046 of our APC invoices; the total spend (including taxes) of some EUR 1.3 million results in an average APC value of EUR 1,258 for the Max Planck Society. Similar values are also reported by several of the German universities that are being supported by the German Research Foundation (DFG) to build up their own publication funds. They upload their APC data to the same system, bringing the total record to 2,387 articles, with a total expenditure of almost EUR 3 million and an average APC fee of EUR 1,239. ${ }^{6}$

\footnotetext{
${ }^{6}$ Jochen Apel et al. (2014-): Datasets on fee-based open access publishing across German institutions. Bielefeld University. https://github.com/OpenAPC/openapc-de (figures as of 4 April 2015; data will constantly be expanded).
}

The figures reported by the Austrian Science Fund (FWF) are very similar to the collective data from Germany. An average Gold APC of EUR 1,282 could be observed in 2014, constituting a slight decrease compared with the 2013 figure of EUR $1,393 .^{7}$

According to initial findings of the SCOAP3 Consortium, the publication costs per article in that sector are actually just under EUR 1,100, despite previously expensive subscription journals from the field of physics being switched to a publication cost model in $2014 .^{8}$

The Wellcome Trust was the first body to make its APC records public. Its recent annual report for 2013-2014 is already its second. In the past year, some 2,556 articles have been published under an APC model with Wellcome support, and the total spend for the year 2013-2014 was just under $£ 4.7$ million (EUR 6.4 million). The average APC was around $£ 1,837$ (EUR 2,495). ${ }^{9}$ The crucial reason why Wellcome's average fee is significantly higher than the German, Austrian, and SCOAP3 figures lies in the fact that the Wellcome Trust like the Research Councils $\mathrm{UK}^{10}$ - includes hybrid APCs, which are not only much higher than most pure open access costs but are also widely considered not to reflect a true market value. In Germany and many other countries, hybrid APCs are excluded from the central funding schemes. The Wellcome Trust's report shows that hybrid articles account for $75 \%$ of their total; if we consider only their articles in pure open access journals, then the average APC goes down to $£ 1,241$ (EUR 1,686). This figure is closer to the German evidence but still higher. One explanation might be that the Wellcome Trust puts no limit on APCs, while in other countries (such as Germany) these costs are very often capped or made subject to some co-funding from research budgets.

All the available evidence that has been published or discussed in various reports points consistently to a predicted APC level of well below EUR 2,000 in a purely open access scenario. There is a comfortable margin of error before

\footnotetext{
${ }^{7}$ Falk Reckling, Katharina Rieck (2015): Austrian Science Fund (FWF) publication cost data 2014. http://dx.doi.org/ 10.6084/m9.figshare.1378610. Falk Reckling, Margit Kenzian (2014): Austrian Science Fund (FWF) publication cost data 2013. http://dx.doi.org/10.6084/m9.figshare.988754.

${ }^{8} \mathrm{http}$ //scoap3.org/scoap3journals/journals-apc. See also Clément Romeu et al. (2014): The SCOAP3 initiative and the open access article-processing-charge market: global partnership and competition improve value in the dissemination of science. DOI:10.2314/CERN/C26P.W9DT.

${ }^{9}$ http://blog.wellcome.ac.uk/2015/03/03/the-reckoning-ananalysis-of-wellcome-trust-open-access-spend-2013-14/.

${ }^{10}$ RCUK reports: "The subset of 55 institutions reported spending a total of $£ 10.4$ million on APC payments during the first year, resulting in 6,504 gold papers. This implies an average APC (including VAT) of $£ 1,600$ ". Cf. Review of the Implementation of the RCUK Policy on Open Access (2015), p. 11. http://www.rcuk.ac.uk/research/openaccess/2014 review/.
} 
spending would reach the current level of between EUR 3,800 and 5,000, so it must be safe to assume that the money in the system is sufficient, and that the transformation to open access can be achieved without any financial risks.

Insight 2

There is currently already enough money in the system. A large-scale transformation from subscription to open access publishing is possible without added expense.

\section{APC breakdown by country}

In order to make reliable cost projections, the necessary next step is to break down the global publishing figures to country and eventually also institutional levels. ${ }^{11}$ For such an exercise to be meaningful it is essential to apply a key principle of the open access business model, according to which not all publications that are legitimately listed in national or institutional bibliographies are cost-relevant, but only those where the corresponding author is affiliated to the given country or institution. For good reasons, multi-authored papers will be captured in the bibliographies or institutional repositories of all their home institutions, but in terms of cost-relevance each of these multi-counted papers needs to be paid for only once. For the time being, the dominant model is that the corresponding author is responsible for picking up and settling the invoice. Therefore the various national and institutional publishing lists must be de-duplicated to reflect the corresponding author papers only, in order to make accurate budget forecasts.

For our country-level analysis, we took Germany, the UK, and France as examples - Germany being our home ground, the UK being the current hot spot in the aftermath of the Finch report, and France having recent media coverage of leaked information about their national publisher agreements. The following graphic, based on data from the Web of Science, shows the publication outputs (articles and reviews) from these countries over the past 10 years. The consistent pattern is that the proportion of corresponding author papers is in the range of $65-70 \%$ of the total country output, which means that only this subset of articles is cost-relevant. If the entire country's output were to be financed under a purely open access business model, only this $65-70 \%$ share would be billed in this country, while in the remaining third of cases the costs are incurred abroad. Though the proportion may show some variation from year to year or from country to country, it will never amount to $100 \%$.

${ }^{11}$ The MPDL data analysis is documented in a separate publication, which includes also data files. See Margit Palzenberger (2015): "Number of scholarly articles per country. Data on Web of Science listed articles and reviews 2004-2013". http://dx.doi.org/10.17617/1.2.
For the publishing year 2013, this breakdown shows the following cost distribution for each of the three countries in our example:

- For Germany, we can identify 70,000 APC-relevant papers of a total of 103,000 research articles and reviews listed in the Web of Science. Multiplied by our assumed EUR 2,000 average APC price, the expected open access expenditure for Germany in 2013 would have been in the region of EUR 140 million. There are no consolidated figures for the country-wide subscription spending for scientific journals, but experts project these costs to be well beyond EUR 200 million per year. So Germany should be in a position to organize a large-scale open access transformation without much pain.

- For the $U K$, we can identify 72,000 APC-relevant papers of a total of 109,000 research articles and reviews listed in the Web of Science. Multiplied by our assumed EUR 2,000 average APC price, the expected open access expenditure for the UK in 2013 would have been in the region of EUR 144 million. Estimates of what the UK's higher education institutions are paying for their journal subscriptions vary from $£ 160$ million per year (according to Jisc Collections) to $£ 192$ million (according to Research Libraries UK): that is, between EUR 218 and 260 million. So for the UK, too, we have a clear picture that a comprehensive open access transformation could be done without financial stress.

- For France, we can identify 46,000 APC-relevant papers of a total of 71,000 research articles and reviews listed in the Web of Science. Multiplied by our assumed EUR 2,000 average APC price, the expected open access expenditure for France in 2013 would have been in the region of EUR 92 million. According to conservative estimates, it is assumed that the French academic sector is paying at least EUR 120 million per year for their subscriptions to scientific journals. So, like Germany and the UK, France needs to anticipate no difficulties in preparing for an open access transformation (Figure 1).

It will be interesting to see comparable data analyzed for the USA as the biggest information market and largest producer of research papers. With funding from the Mellon Foundation, a new project has recently been launched to investigate a sustainable model of open access APCs for large North American research institutions. ${ }^{12}$ The adopted name for the project, 'Pay It Forward', reflects a similar philosophy to that laid out in this paper. According to our own analysis of the US market we would expect a share of $80 \%$ corresponding authors' papers $(309,000$ of the 388,000 research articles and reviews listed in the Web of Science in 2013) amounting to an estimated EUR 618 million of open access costs for the entire USA. ${ }^{13}$ From what we know, we assume that there is

\footnotetext{
${ }^{12}$ http://payitforward-project.ucdavis.edu/.

${ }^{13}$ Cf. note 11.
} 
Total publication volume
Articles and reviews in Web of Science

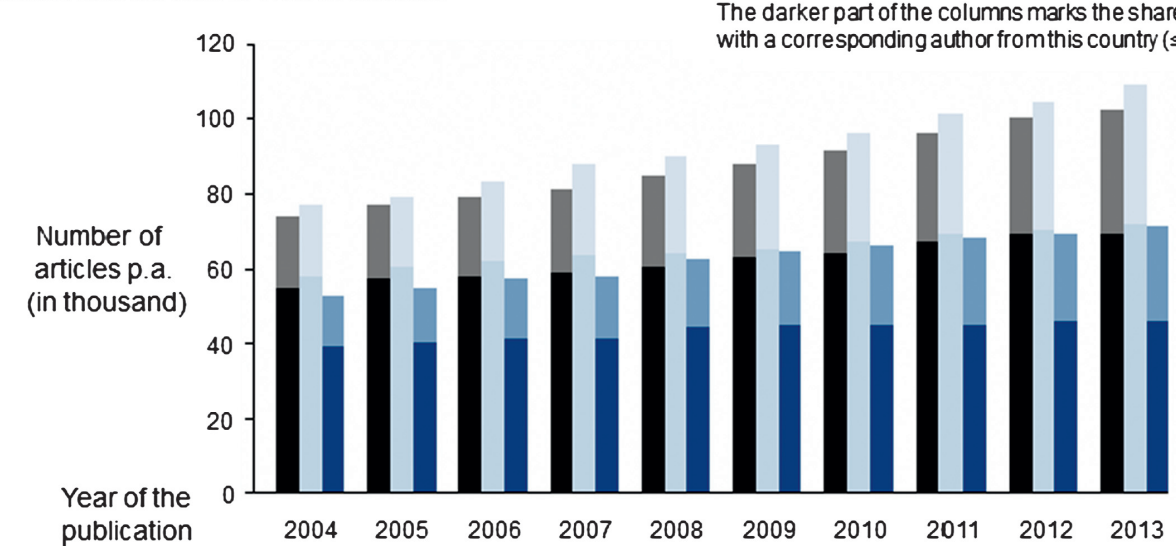

Figure 1. Publication volume with APC-relevant share of selected European countries.

enough money available through subscriptions in the USA to make the transformation affordable there as well.

In general, our data analysis indicates a certain correlation between the country output and the share of corresponding author papers. This means that countries with lower output numbers can expect a lower share of APC cost-relevant corresponding author papers, while higher output numbers correlate with a higher share. The regional, linguistic, and political background of a country also seems to play a role. In China, Japan, South Korea, India, and Brazil we see a higher share of corresponding author papers than in the European countries, while Canada's position resembles that of Europe. We invite our readers to examine their country's performance as documented in our supplementary data publication ${ }^{14}$ and to compare this evidence with their current national subscription spending.

\section{Insight 3}

For a meaningful cost analysis it is important to differentiate the APC-relevant articles (corresponding author papers) from the rest of the publication record. Early examples at the country level further substantiate the claim that an open access transformation can be achieved without financial risk.

\section{APC breakdown by institution}

The viability we have shown to hold at the country level applies even more dramatically in institutional settings. Research is done in collaboration across institutional and national boundaries. A large proportion of research papers

\footnotetext{
${ }^{14}$ Cf. note 11.
}

have multiple authorship and very often emerge from more than one institution. We have already seen at the country level that the share of corresponding authors varies from country to country and is always well below $100 \%$. This share is reduced even further at the institutional level. As a large proportion of research collaboration is organized domestically between various institutions in the same country, the published output will again be captured in several bibliographies and perhaps repositories, but each paper will be paid for only once. Our evidence suggests that the quantity of APC-relevant publications for a given institution lies somewhere between $40 \%$ and $60 \%$ of their total output, depending on the research intensity and reputation of the research institution. Figures at this level are reported by some 30 German universities that are participating in the DFG's APC funding program.

In our own case at the Max Planck Digital Library, we can look back on more than 10 years of running a dedicated program for supporting the APCs of our researchers. We are among the most experienced libraries in the world in handling APCs, and we have continually been monitoring developments and analyzing our findings. From our experience, we perceive a persistent pattern that is valid across the various open access publishers and stable over time. Our robust formula is that we expect our authors' papers to generate invoices for between $50 \%$ and $60 \%$ of the total number of papers (in fact, for some publishers we observe shares of corresponding author papers even as low as $40 \%$ ). Already we feel confident enough to base further cost projections on this value. For instance, as the current annual journal article output of all Max Planck Institutes is in the region of 10,000 papers, we anticipate the APC-relevant share to be a maximum of 6,000 . Hence, our projected costs for a complete transformation scenario would be no more than EUR 12 million. The Max Planck Society is a heavily output-oriented research organization and, at the same time, a big buyer of research information. Our current spending on journal subscriptions is already substantial enough to make the big open access transformation possible 
without having to ask for extra money. If we, as a very research-intensive organization, can make it, then we believe that most others should also be able to organize the transformation within their current budget provisions.

\section{Insight 4}

While the APC-relevant article share at a country level is very often around $70 \%$, it can easily go down to about $50 \%$ at the institutional level. This fundamental principle of allocation must be considered when calculating the costs for an open access transformation.

\section{OPENING THE DOOR}

The vision of a truly open access publishing system was already a constitutive (albeit implicit) element of the earliest open access declarations and has been perpetuated ever since in many further resolutions and open access policy statements. The energetic recent initiatives, particularly in the European context, along with the momentum in so many fields of scholarly publishing, have ushered open access to our threshold. It seems that we just have to open the door and let it in. We need to open the door to a change in the underlying business model of scholarly publishing, making the shift from subscription-based payments to open access services-based payments. The current subscription model needs to be further developed into a truly transitional model. The modern offsetting models that seem to mushroom everywhere with their correlation of open access publishing entitlements with subscription spending are the most promising elements that we have at the moment. Such dual-use models must be requested much more energetically by the research libraries on behalf of their constituencies. The offsetting principle is finally opening up the subscription system and starting to bring it into some alignment with open access requirements. As a consequence, the library acquisition budget is losing the hermetic seal that dates back to the print era and that has remained so pervasive in the daily routines of most libraries. Finally, the libraries and consortia of the world are beginning to live up to the expectations that have been raised by the many open access resolutions of the past decade.

Broadening the scope of subscription agreements and of library acquisition budgets is a necessary but not sufficient step. We libraries must also be more aware of the demographics of the published research output than ever before. In a world based on open access business models a new stratification of services and costs will emerge, requiring new criteria for the selection and aggregation processes in the libraries, for their internal workflows, and for the necessary tools and skills that they will employ. The transactions that need to be organized by the libraries on behalf of their patrons will be very different in an open access world compared with the subscription system. There will need to be a new billing and supporting infrastructure, starting at submission, to make the system robust and scalable for large publishing volumes. Work on this has already begun, as exemplified, for instance, in the Efficiency and Standards for Article Charges (ESAC) initiative. ${ }^{15}$

Regardless of some regional specialties, scientific publishing is a truly international enterprise. Therefore a fundamental change in the underlying business model can only be achieved on a global scale. The world's research organizations, together with their libraries, need to act jointly and with some coordination, with the key aim of shifting the money out of the subscription system and so that it can be re-invested in open access publishing. This coordinated move will also give an unambiguous message to the publishers, so that they themselves can adapt to the new business model with confidence in its financial sustainability for the future. In the end, neither the libraries nor the publishing houses need lose their roles; all the players will be transformed, emerging with new vigor in a modernized publishing system.

The time is ripe for the global research community to accelerate the transition to open access. We have the crucial opportunity to transform the underlying business model of journal publishing while protecting the financial viability and core functionalities of the publishing system at large. Ultimately, all subscription spending must be stopped: this is the simple culmination of the incremental steps of the past decade. The significant savings can then be reinvested for the co-creation of a range of publishing services that will truly serve the scholarly endeavors of the 21 st century.

\section{COMPETING INTERESTS}

The authors declare no competing interests.

\section{PUBLISHING NOTES}

(C) 2015 Schimmer et al. This work has been published open access under Creative Commons Attribution License CC BY 4.0, which permits unrestricted use, distribution, and reproduction in any medium, provided the original work is properly cited. Conditions, terms of use and publishing policy can be found at www.scienceopen.com.

Please note that this article may not have been peer reviewed yet and is under continuous post-publication peer review. For the current reviewing status please click here or scan the QR code on the right.

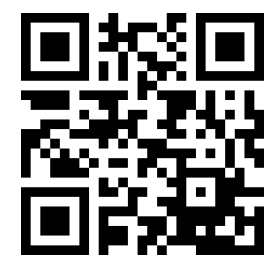

\section{ScienceOPEN.com \\ research+publishing network}

\footnotetext{
${ }^{15}$ http://esac-initiative.org/.
} 